М.А. Кокотова*

\title{
ГОСУДАРСТВЕННЫЙ СОВЕТ ФРАНЦИИ КАК ОРГАН КОНСТИТУЦИОННОГО КОНТРОЛЯ
}

Аннотация: Предметом рассмотрения данной статьи является место Государственного совета в системе французского конституционного контроля и его компетенция в данной сфере. Показано значение Государственного совета для формирования современной системы конституционного контроля, предполагающей осуществление названного контроля параллельно несколькими органами, наделенными различным объемом полномочий. Очерчена история появления и развития Государственного совета, влияние на его назначение и компетенцию доктринальных представлений различных периодов истории Франции, связанных с пониманием принципа разделения властей. Автор основывается на диалектическом подходе. В качестве специальных методов исследования права применяются институциональный, историко-правовой и формально-юридический методы познания. Делается вывод о том, что учреждение Государственного совета задолго до появления во Франции конституционного контроля и создания Конституционного совета, ставшее следствием широкого распространения доктрины парламентского суверенитета, предопределило создание во Франции современной системы, при которой конституционной контроль законов и актов органов исполнительной власти осуществляется разными органами. Этот пример демонстрирует влияние, оказываемое на практику государства даже тех идей, от которых уже отказалась доктрина.

Ключевые слова: Государственный совет, Конституционный совет, конституционный контроль, административная юстиция, общая воля, суверенитет парламента, верховенство законов, принцип разделения властей, контроль конституционности законов, контроль регламентарных актов.

DOI: 10.7256/1994-1471.2014.6.11440

$\mathrm{C}$ овременная организация конституционного контроля во Франции представляет результат соединения доктринальных воззрений различных периодов французской истории и практической необходимости. Хотя Франция принадлежит к романо-германской модели конституционного контроля, в ней реализован не самый распространенный ее вариант, предполагающий осуществление такого контроля несколькими органами, наделенными различным объемом полномочий (в их числе помимо Конституционного совета называют Государственный совет, Кассационный суд и подчиненные им суды). Распределение полномочий между ними сложилось исторически и поэтому представляет собой довольно сложную схему. Основным полномочием Государственного совета в этой системе является проверка конституционности актов органов исполнительной власти.

Государственный совет был образован не просто задолго до Конституционного совета, а в то время, когда создание органа, проверяющего конституционность законов, казалось немыслимым. Причиной такого отношения является доктрина парламентаризма, согласно которой принятие властью решений должно основываться на общей воле народа, выражаемой через его представителей. Как отмечает И. Мадьо: «здесь сказывается влияние ЖанЖака Руссо, для которого закон не мог быть ни ошибкой, ни орудием угнетения ${ }^{1} \gg$. Парламент, состоящий из представителей различных социальных групп, является в этой концепции выразителем воли народа и способом осуществления народом своей власти. Предполагалось, что представители народа всегда будут действовать в его интересах, а следовательно, их решения всегда будут разумны и справедливы.

Из понимания Парламента как выразителя народного суверенитета логично следует идея невозможности ограничения его власти, в том числе путем проверки его решений. В то же время контроль за актами органов исполнительной власти, не избираемыми народом,

Madiot Y. Institutions politiques de la France. P., 1995. P. 56.

(C) Кокотова Мария Александровна

* Аспирантка кафедры конституционного права, Уральская государственная юридическая академия [km231089@yandex.ru]

620137, Россия, г. Екатеринбург, ул. Комсомольская, д. 21. 
считался не только возможным, но и необходимым. В силу этого конституционный контроль законов во Франции появился достаточно поздно. В то же время контроль за органами исполнительной власти возник вскоре после Великой Французской революции.

Для осуществления этого контроля на восьмом году Республики, то есть Конституцией 1800 года, был создан Государственный совет, а «свою сегодняшнюю форму он приобрел в конце XVIII и в начале XIX века по Конституции VIII года Республики, то есть при Бонапарте»².

Государственный совет является высшей инстанцией в таком специфическом образовании, как система административной юстиции. Возникновение административной юстиции является следствием реализации на практике принципа разделения властей так, как он понимался в конце XVIII - начале XIX века. Предполагалась, что разделение властей должно обеспечивать их максимальную независимость друг от друга, а этому противоречила возможность судебного контроля иных ветвей власти. Независимость исполнительной власти от судебной должен был обеспечить отказ от судебного контроля за органами исполнительной власти и передачу полномочий по этому контролю самим органам исполнительной власти. Административная юстиция была создана как система специализированных органов исполнительной власти, уполномоченных контролировать остальные органы.

В настоящее время административная юстиция уже является скорее подсистемой судебной власти со специфической компетенцией․․ Соответственно, изменилось и положение Государственного совета. Он был создан прежде всего как советник правительства ${ }^{4}$ и затем как высшая инстанция в системе административных судов $^{5}$. Хотя вначале «вторая функция была развита менее, чем первая ${ }^{6} »$, с течением време-

\footnotetext{
Брэбан Г. Французское административное право: Пер. с фр. М., 1988. С. 400.

3 Про административную юстицию см., напримep: Sauvé J. - M. La justice administrative à l'aube de la décennie 2010 : quels enjeux? quels défis? Intervention sur la conférence nationale des présidents des juridictions administratives <//http ://www.conseil constitutionnel.fr // Documentation // Contributions et discours $>$ (последнее посещение - 9 марта 2014 г.)

4 Stirn B. Le Conseil d'Etat: son rôle, sa jurisprudence. P., 1991. P. 39.

5 Во Франции действует Кодекс административной юстиции, составной частью которого является книга первая - Государственный совет, книга вторая - Административный трибунал и административные апелляционные суды и т. д.
}

6 Debbasch C., Ricci J. - C. Contentieux administratifs. P., 2001. P. 58. ни она приобретала все большее значение. За время своего существования Государственный совет существенно укрепил свое положение и расширил полномочия. В его развитии выделяют следующие ключевые моменты:

1806 г. - появление у Совета судебной функции и, соответственно, последующего конституционного контроля ${ }^{7}$.

1872 г. - достижение широкого практического освоения судебной функции, «золотой век административного правосудия» ${ }^{8}$.

1963 г. - реформа, в результате которой была создана современная структура Государственного совета'.

Специфика осуществления Государственным советом конституционного контроля связана с особенностями правовой природы этого органа. Государственный совет, возникший еще до распространения идей Кельзена о создании специализированных органов, осуществляющих конституционный контроль, конечно, не был образован как такой орган. Безусловно, контроль законности актов органов исполнительной власти, осуществляемый Государственным советом, предполагает, в том числе, проверку их конституционности, и в настоящее время Государственный совет активно осуществляет такую проверку. Однако о возникновении конституционного контроля во Франции уже в 1800 г. можно говорить с большой долей условности.

По первоначальному замыслу вряд ли вообще предполагалась возможность какого-либо контроля за нормотворчеством. Ведь допуская возможность контроля за актами исполнительной власти, революционеры-создатели Конституции одновременно старались лишить эту власть регламентарных полномочий ${ }^{10}$, предоставив эти полномочия свободному от контроля Парламенту. Впрочем, когда «эта прекрасная абстракция столкнулась с конкретной реальностью ${ }^{11}$, правительство получило возможность принимать нормативные правовые акты, а Государственный совет возможность проверять эти акты с точки зрения их законности.

Однако в любом случае создание Государственного совета предопределило разделение компетенции в существующей в настоящее время системе контроля конституционности правовых актов.

\footnotetext{
Morand-Deviller J. Droit administratif. P., 2011. P. 23.

Chevallier V. Science administratif. P., 1986. P. 29.

9 Chapus R. Droit du contentieux administratif. P., 1995.

10 Morand-Deviller J. Op. cit. P. 317.

11 Ibid P. 317
} P. 56. 
Данная система возникла в результате преодоления доктрины суверенитета парламента. Разумеется, эта доктрина никогда не воспринималась буквально, и уже в XVIII веке выдвигались концепции ограничения законодательной власти. Такой концепцией было предоставление королю права вето, как способ контроля за резолюциями парламентариев ${ }^{12}$. Ограничение власти парламента предполагает идея Монтескье о разделении властей, которое выступает как «самая сильная гарантия, которая может существовать», в той мере, в какой она была задумана как механизм, и заставляющий власти конкурировать, и провоцирующий, как следствие, стратегии защиты в их сфере, которые должны привести ... к соблюдению Конституции ${ }^{13}{ }^{\prime}$.

Однако эти концепции не предполагали создание самостоятельного органа, уполномоченного осуществлять контроль конституционности законов. Только в XX веке распространение концепций конституционного контроля в Европе и соображения внутренней политики руководства Франции в совокупности с очевидной неадекватностью идеи верховенства закона действительности потребовали введения института конституционного контроля законов. Поэтому ныне действующая Конституция Франции, принятая в 1958 г., предусмотрела создание Конституционного совета органа, уполномоченного контролировать конституционность законов до их вступления в силу. Тем самым практика произвела в доктрине «коренной перелом, освободившись от легисцентристской концепции, унаследованной от Руссо ${ }^{14}$ ».

Таким образом, во Франции возникла система конституционного контроля, осуществляемого параллельно двумя независимыми органами.

Разграничение компетенции между Конституционным и Государственным советами было проведено по кругу рассматриваемых актов. Государственный совет вправе осуществлять конституционный контроль в отношении регламентарных актов (т. е. актов органов исполнительной власти), Конституционный совет - в отношении законов. В настоящее время такое разграничение является не совсем точным, так как Государственный совет, как указывают исследователи, непосредственно связан не только с исполнением,

12 Rousseau D. Droit du contentieux constitutionnel. P., 2010. P. 12.

\section{Ibid P. 12.}

14 Morabito M. Histoire constitutionnelle de la France de 1789 à nos jours. P., 2010. P. 437. но и «с подготовкой, принятием ${ }^{15}$ » законов и, в том числе, участвует и в проверке их конституционности.

Во-первых, Государственный совет дает заключения на проекты законов, вносимые правительством, причем их предоставление на рассмотрение Государственного совета является обязательным ${ }^{16}$. Впрочем, проект рассматривается Государственным советом на стадии внесения законодательной инициативы, а после принятия закона парламентом он рассматривается еще раз Конституционным советом. Поэтому мнение Государственного совета «не является «страховкой от всех рисков», ведь может случиться, что Конституционный совет выскажется иначе по вопросу о конституционности закона ${ }^{17}$ ». К тому же, они «даются правительству, а не общественному мнению ${ }^{18}$ » и потому не подлежат опубликованию.

Во-вторых, Государственный совет участвует в контроле конституционности вступивших в силу законов, проверяя допустимость жалоб, направленных в Конституционный совет через подчиненные ему административные суды или представленные ему непосредственно.

Это дает исследователям основание писать о контроле конституционности законов, осуществляемом Государственным советом ${ }^{19}$, хотя, конечно, участие Государственного совета в этом контроле является довольно опосредованным. При этом сам Государственный совет в своих решениях указывал, что такой контроль не входит в его полномочия ${ }^{20}$.

Роль Государственного совета в развитии конституционного контроля не ограничивается осуществлением предоставленных ему в данной сфере полномочий. Поскольку Госу-

15 Пилипенко А. Н. Принципы юридической безопасности во французском праве//Журнал зарубежного законодательства и сравнительного правоведения. 2013. № 4. С. 647.

16 Code de justice administrative < http: // www. legifrance. gouv.fr/ affichCode.do? cidTexte=LEGITEXT000006070933 \&dateTexte $=20140310>$ (последнее посещение -10 марта 2014 г.)

17 Там же С. 39.

18 Debbasch C. Science administratif. P., 1989. P. 703.

19 См., например, Sauvé J. - M. L'examen de la constitutionnalité de la loi par le Conseil d'État Journée d'étude organisée au Conseil d'État par le Centre de recherche en droit constitutionnelde l'Université de Paris I Panthéon-SorbonneVendredi 1er avril $2011</ /$ http:// www.conseil d'Etat.fr // Documentation // Contributions et discours> (последнее посещение - 9 марта 2014 г.)

20 CE, 5 janvier 2005, № 257341, recueil Lebon <http:// www.legifrance.gouv.fr/affichJuriAdmin.do?oldAction $=$ re chJuriAdmin\&idTexte $=$ CETATEXT000008235854\&fastR eqId=1736161534\&fastPos=3> (последнее посещение 13 марта 2014 г.) 
дарственный совет возник значительно раньше Конституционного совета, многие разработанные им конструкции были восприняты Конституционным советом. Прежде всего Государственным советом разработано понятие общего принципа права ${ }^{21}$. Позиция о возможности признания неконституционным пробела в праве также была впервые сформулирована Государственным советом ${ }^{22}$.

Интересно и то, что Конституционный совет в некоторых аспектах повторил историю развития Государственного совета. Во-первых, как Государственный, так и Конституционный советы первоначально осуществляли только предварительный контроль, к которому впоследствии прибавился последующий. Во-вторых, оба эти органа, формально осуществляя лишь контроль, фактически активно занимались нормотворчеством ${ }^{23}$. В-третьих, и Государственный и Конституционный советы по мере своего существования становились все более значимыми органами, причем их компетенция была существенно дополнена их собственной практикой ${ }^{24}$, что, впрочем, является проявлением общей тенденции «усиления роли судебной власти ${ }^{25} »$.

Система конституционного контроля Франции демонстрирует то, как идеи, от которых уже отказалась доктрина, продолжают жить в практике в силу сложившейся традиции и того,

${ }^{21}$ Sauvé J. - M. Szafran C. Introduction historique au contrôle de l'administration en droit français Séminaire «Internationalisation du droit» franco-chinois Pékin 6-

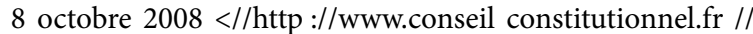
Documentation // Contributions et discours $>$ (последнее посещение - 9 марта .2014 г.)

22 Sauvé J. - M., Szafran C. Intervention à la conférence sur "La réforme de la justice administrative Faculté de droit de Poitiers Vendredi 28 novembre $2008</ / h t t p$ ://www.conseil constitutionnel.fr // Documentation // Contributions et discours> (последнее посещение - 9 марта 2014 г.)

23 О роли нормотворчества Государственного совета см., например: Pourhiet A . - M. Droit constitutionnel. P., 2012. P. 68.; Lochak D. La justice administrative. P., 1998. P. 114.

24 Конечно, существуют и различия. Возникнув в разное время, конституционный контроль законов и конституционный контроль регламентарных актов обладают в силу этого разными характеристиками Конституционный контроль законов изначально был только предварительным, конституционный контроль регламентарных актов возник сразу как последующий. Контроль законов осуществляется специально созданным для этого органом в порядке специализированного конституционного процесса, а контроль регламентарных актов - судом, в рамках административного судопроизводства.

25 Карпенко К. В. Институт последующего (конкретного) конституционного контроля во Франции // Журнал зарубежного законодательства и сравнительного правоведения. 2013. № 5. С. 781. что отказ от них потребовал бы радикального изменения практики. Ведь сейчас необходимость строгого соблюдения принципа разделения властей, не допускающего какого-либо взаимодействия между ветвями власти, уже не признается, как и то, что деятельность органов исполнительной власти не может контролироваться другими ветвями власти. Однако разделение двух видов конституционного контроля осталось и в настоящее время оно обоснованно с организационной точки зрения. Поэтому вполне логично предоставление полномочий по контролю конституционности актов органов исполнительной власти Государственному совету, который уже осуществляет контроль законности этих актов и их соответствия международным нормам. К тому же споры о конституционности акта органически связаны со спорами о применении этих актов, которые рассматриваются органами административной юстиции, поэтому удобнее не передавать вопрос о конституционности в другой орган, а оставить его на рассмотрение того, кто разрешает основной спор.

Кроме этого, Конституционный совет на сегодняшний день не имеет ресурсов для проверки всех правовых актов, и французский законодатель не высказывает желания реформировать данный орган. В соответствии со статьей 56 Конституции Франции ${ }^{26}$ Конституционный совет состоит всего из 9 назначаемых членов, к которым прибавляются члены по праву, к которым относятся бывшие президенты Республики (в этом качестве они остаются членами Совета пожизненно). В Конституционном совете нет палат, секций или иных структурных подразделений, все дела рассматриваются на совместном заседании, что также уменьшает число дел, которые могут быть рассмотрены Конституционным советом за ограниченный промежуток времени.

У Государственного совета, напротив, есть достаточный для осуществления такого масштабного контроля кадровый и административный ресурс. В отличие от Конституционного совета, Государственный совет имеет сложную структуру: он возглавляется вице-председателем и состоит из секций, каждая из которых имеет собственный круг полномочий: секция, рассматривающая судебные споры, секция и пять секций, осуществляющих консультирование правительства. Помимо этого, Кодекс административной юстиции предусматривает множество различных форм принятия решений Государственным советом: коллегиальное

26 Конституция Французской Республики от 4 октября 1958 г. // Конституции зарубежных государств. М., 2009. C. 74 . 
принятие решений на пленарном собрании или на секции, причем состав присутствующих может варьироваться в зависимости от дела, и единоличное принятие решений ${ }^{27}$. Передача конституционного контроля актов органов исполнительной власти Конституционному совету потребовала бы его переформирования, тогда как сохранение этого полномочия за Государственным советом позволят обойтись без организационных изменений.

\section{Библиография:}

1. Брэбан Г. Французское административное право. - Пер. с фр. - М.: Прогресс, - 1988.

2. Chapus R. Droit du contentieux administratif. - P: Montchrestien Editions, E.J.A., 1995. - 1121 p.

3. Chevallier V. Science administratif. - P: Presses Universitaires Françaises, 1986. - 592 p.

4. Debbasch C. Science administratif. - P: Editions dalloz, 1989. - 815 p.

5. Rousseau D. Droit du contentieux constitutionnel. - Paris: Montchrestien., Lextenso éditions, 2010. 586 p.

6. Sauvé J. - M. La justice administrative à l'aube de la décennie 2010 : quels enjeux ? quels défis ? < http://www.conseil-etat.fr/node.php?articleid=2136 > (последнее посещение - 9 марта 2014 г.)

7. Sauvé J. - M. L'examen de la constitutionnalité de la loi par le Conseil d'État (последнее посещение9 марта 2014 г.)

8. Sauvé J. - M. Szafran C. Introduction historique au contrôle de l'administration en droit français < http://www.conseil-etat.fr/node.php?articleid=332 > (последнее посещение - 9 марта 2014 г.)

9. Sauvé J. - M., Szafran C. Intervention à la conférence sur «La réforme de la justice administrative»< http://www.conseil-etat.fr/node.php?articleid=339 > (последнее посещение - 9 марта 2014 г.)

10. Lochak D. La justice administrative. - P: Editions Montchrestien, E. J. A., 1998. - 531 p.

11. Madiot Y. Institutions politiques de la France. - Paris: Editions Dalloz, 1995. - 143 p.

12. Morabito M. Histoire constitutionnelle de la France de 1789 à nos jours. - P: Montchrestien., Lextenso éditions, 2010. - 543 p.

13. Morand-Deviller J. Droit administratif. - P: Montchrestien., Lextenso éditions, 2011. - 776 p.

14. Pourhiet A . - M. Droit constitutionnel. - Paris: Editions economica, 2012. - 531 p.

15. Stirn B. Le Conseil d'Etat: son rôle, sa jurisprudence. - Paris: Editions Nachetes, 1991. - 145 p.

16. Карпенко К.В. Институт последующего (конкретного) конституционного контроля во Франции // Журнал зарубежного законодательства и сравнительного правоведения. - 2013. № 5. - С. 780-790.

17. Пилипенко А.Н. Принцип юридической безопасности во французском праве // Журнал зарубежного законодательства и сравнительного правоведения. - 2013. № 4. - С. 646-652.

\section{References:}

1. Breban G. Frantsuzskoe administrativnoe pravo. - Per. s fr. - M.: Progress, -1988.

2. Chapus R. Droit du contentieux administratif. - P: Montchrestien Editions, E.J.A., 1995. - 1121 p.

3. Chevallier V. Science administratif. - P: Presses Universitaires Françaises, 1986. - 592 r.

4. Debbasch C. Science administratif. - P: Editions dalloz, 1989. - 815 r.

5. Rousseau D. Droit du contentieux constitutionnel. - Paris: Montchrestien., Lextenso éditions, 2010. 586 r.

6. Sauvé J. - M. La justice administrative à l'aube de la décennie 2010 : quels enjeux ? quels défis ? < http://www.conseil-etat.fr/node.php?articleid=2136 > (poslednee poseshchenie - 9 marta 2014 g.)

7. Sauvé J. - M. L'examen de la constitutionnalité de la loi par le Conseil d'État (poslednee poseshchenie9 marta 2014 g.)

8. Sauvé J. - M. Szafran C. Introduction historique au contrôle de l'administration en droit français < http://www.conseil-etat.fr/node.php?articleid=332 > (poslednee poseshchenie - 9 marta 2014 g.)

9. Sauvé J. - M., Szafran C. Intervention à la conférence sur « La réforme de la justice administrative» < http://www.conseil-etat.fr/node.php?articleid=339 > (poslednee poseshchenie -9 marta 2014 g.)

10. Lochak D. La justice administrative. - P: Editions Montchrestien, E. J. A., 1998. - 531 p.

11. Madiot Y. Institutions politiques de la France. - Paris: Editions Dalloz, 1995. - 143 r.

Code de justice administrative < http: // www. legifrance. gouv.fr/ affichCode.do? cidTexte=LEGITEXT000006070933 \&dateTexte=20140310> (последнее посещение - 10 марта 
12. Morabito M. Histoire constitutionnelle de la France de 1789 à nos jours. - P: Montchrestien., Lextenso éditions, 2010. - $543 \mathrm{r}$.

13. Morand-Deviller J. Droit administratif. - P: Montchrestien., Lextenso éditions, 2011. - 776 r.

14. Pourhiet A. - M. Droit constitutionnel. - Paris: Editions economica, 2012. - 531 p.

15. Stirn B. Le Conseil d'Etat: son rôle, sa jurisprudence. - Paris: Editions Nachetes, 1991. - 145 r.

16. Karpenko K.V. Institut posleduyushchego (konkretnogo) konstitutsionnogo kontrolya vo Frantsii // Zhurnal zarubezhnogo zakonodatel'stva i sravnitel'nogo pravovedeniya. - 2013. № 5. - C. 780-790.

17. Pilipenko A.N. Printsip yuridicheskoi bezopasnosti vo frantsuzskom prave // Zhurnal zarubezhnogo zakonodatel'stva i sravnitel'nogo pravovedeniya. - 2013. № 4. - C. 646-652.

Материал поступил в редакцию 13 марта 2014 г. 